\title{
Manipulation of polyunsaturated, branched- chain and trans-fatty acid production in Shewanella putrefaciens strain ACAM 342
}

\author{
David S. Nichols, ${ }^{1}$ Tom A. McMeekin ${ }^{1}$ and Peter D. Nichols ${ }^{1,2}$ \\ Author for correspondence: David S. Nichols. Tel: +61 02 202637. Fax: +61 02202642. \\ e-mail: D.Nichols@agsci.utas.edu.au
}

\section{Australian Collection of Antarctic Microorganisms, Cooperative Research Centre for the Antarctic and Southern Ocean Environment and Department of Agricultural Science, University of Tasmania, GPO Box 252C, Hobart Tasmania 7001, Australia \\ 2 CSIRO Division of Oceanography, Marine Laboratories, GPO Box 1538, Hobart, Tasmania 7001, Australia}

\begin{abstract}
Shewanella putrefaciens strain ACAM 342 produced a range of polyunsaturated fatty acids (PUFA) including 18:2 $166,18: 3 \omega 3,18: 3 \omega 6,18: 4 \omega 3$ and 20:503 (EPA). Under culture in Zobell's broth at $15{ }^{\circ} \mathrm{C}$ exponential-phase cultures produced $3.2 \pm 0.3 \%$ EPA, or $\mathbf{1 . 2} \pm 0.2 \mathrm{mg}$ (g bacterial dry wt) ${ }^{-1}$. Alteration of growth phase, addition of biotin to the medium or a 10-fold decrease in nutrient levels had no significant effect $(P>0.05)$ on levels of EPA. Growth in $7.0 \% \mathrm{NaCl}$ medium markedly decreased the overall degree of fatty acid unsaturation $(P<0.01)$, while growth on acetate as the sole carbon source increased the level of 18:2 $\omega 6$ from $0.4 \pm 0.1 \%$ to $7 \cdot 1 \%$ of total fatty acids through inhibition of branched-chain fatty acid synthesis. Addition of desaturase cofactors to the growth medium increased the proportion of EPA from $3.2 \pm 0.3 \%$ to $4.6 \%$, but decreased the quantitative yield from $1.2 \pm 0.2$ to $0.9 \mathrm{mg}$ (g bacterial dry wt) ${ }^{1}$. This bacterium represents a model organism to study bacterial PUFA production. The trans-monounsaturated fatty acid 16:1 $\omega 7 t$ was also produced under all culture conditions, together with four other trans-isomers, namely $14: 1 \omega 5 t, 15: 1 \omega 6 t, 17: 1 \omega 8 t$ and 18:1 $\omega 7$ t. Although the relative levels of trans-acids also changed under various culture conditions, there was no evidence that they were produced as a starvation or stress response.
\end{abstract}

Keywords: Shewanella putrefaciens ACAM 342, fatty acid production, polyunsaturated fatty acids, psychrotrophs

\section{INTRODUCTION}

Polyunsaturated fatty acids (PUFA) are well known for the beneficial effects they may elicit in a number of human disease conditions such as atherosclerosis and thrombosis, as well as pancreatic, colon and breast cancers (Stansby, 1990; Kelly, 1991; Weber, 1991). PUFA are also economically valuable as feed additives for many mariculture species including oysters, scallops and salmonoid fish, where they greatly increase overall health and growth rate (Langdon \& Waldock, 1981; Bell et al., 1991).

Microbial production of PUFA is an underexploited area of biotechnology. Although numerous bacterial PUFA producers have now been identified (Johns \& Perry, 1977; DeLong \& Yayanos, 1986; Wirsen et al., 1987; Yazawa et al., 1988a, b; Jacq et al., 1989; Intriago \&

Abbreviations: ACAM, Australian Collection of Antarctic Microorganisms; EPA, eicosapentaenoic acid; PUFA, polyunsaturated fatty acids.
Floodgate, 1991; Matsui et al., 1991; Temara et al., 1991; Ringø et al., 1992; Nichols et al., 1993), little is known of the mechanism of PUFA synthesis (Fulco, 1983; Nichols et al., 1993), or growth conditions for their optimal production (Akimoto et al., 1990; Suzuki et al., 1991, 1992).

The fatty acid composition of bacteria may vary considerably with changes in environmental conditions or growth phase. Fujii \& Fulco (1977) reported the normalized rate of desaturase synthesis in Bacillus megaterium reached a maximum as the rate of protein synthesis decreased during the entry to stationary phase. It was proposed that this effect resulted from the reduction in synthesis of a modulator protein responsible for regulating desaturase activity. While the effect of increased desaturase activity was not noted on the fatty acid composition of $B$. megaterium, it may have led to an increase in fatty acid unsaturation.

Considerable data exist on the effects of temperature 
changes on the fatty acid composition of bacterial membranes (for review see Melchior, 1982; Russell, 1984). However, a dramatic change in fatty acid composition is not guaranteed simply by manipulation of growth temperature. Cronan \& Gelmann (1975) estimated the minimum proportion of unsaturated fatty acids required for growth of Escherichia coli to be 15-20\% of the total fatty acids. Several studies have identified bacteria that contain levels of unsaturated components in excess of this minimum level, or high levels of other fluidizing components such as branched-chain fatty acids. The presence of such components may impart a sufficiently low membrane phase transition temperature to enable these bacteria to withstand a large decrease in environmental temperature without the necessity of adjusting membrane fluidity by changes in fatty acid composition.

Bacterial fatty acid composition may also be manipulated by alteration of nutrient levels, osmotic forces, carbon source and biosynthetic cofactors. For example, the relative availability of biotin may affect the fatty acid composition of the organism (Hubbard \& Hall, 1968). Bacillus subtilis ATCC 7059 required biotin as an essential factor for growth (Kaneda, 1966). The level of biotin significantly altered the overall fatty acid composition, where branched-chain fatty acids appeared to be preferentially synthesized under biotin-limited conditions. Similar results were obtained for Bacillus cereus 14B22 by Hubbard \& Hall (1968). The nutrient status of the medium may also influence bacterial fatty acid composition. An example is provided by Fukunaga \& Russell (1990) who found that the fatty acid composition of an Antarctic psychrotrophic Pseudomonas sp. varied widely; in nutrient-poor media, a wider variety of fatty acids were present, including a range of unsaturated fatty acids that were absent when cells were grown in nutrient-rich media.

Prominent among those organisms identified as PUFA producers are strains of Shewanella (Alteromonas) putrefaciens (Yazawa et al., 1988a, b; Akimoto et al., 1990; Matsui et al., 1991; Nichols et al., 1992). This study was undertaken to investigate the effect of such growth conditions on PUFA production, and overall fatty acid composition of Sh. putrefaciens strain ACAM 342.

\section{METHODS}

Bacterial culture. Standard culture conditions are defined as the inoculation of an isolate from solid medium into $10 \mathrm{ml}$ of Zobell's medium (Zobell, 1946) and incubation at $15^{\circ} \mathrm{C}$ until turbid. The $10 \mathrm{ml}$ cultures were then used to inoculate a further $90 \mathrm{ml}$ of medium contained in a $500 \mathrm{ml}$ conical flask (pre-rinsed in chloroform) incubated at $15^{\circ} \mathrm{C}$ and agitated by a magnetic stirrer or orbital shaker (100 r.p.m.) for $15.5 \mathrm{~h}$ until sufficient exponential-phase cell mass was present for harvest. Growth characteristics were previously determined by optical density measurements using a temperature gradient incubator between 0 and $40^{\circ} \mathrm{C}$. Triplicate standard cultures were prepared to assess reproducibility.

To test the effect of growth temperature, strain ACAM 342 was incubated at 10 and $25^{\circ} \mathrm{C}$ in Zobell's medium. At $10^{\circ} \mathrm{C}$ the culture was agitated by a magnetic stirrer, while the $25^{\circ} \mathrm{C}$ broth was agitated by placing in an orbital shaker ( 100 r.p.m.). Cultures were incubated for $9 \mathrm{~h}$ at $25^{\circ} \mathrm{C}$ and for $19 \mathrm{~h}$ at $10^{\circ} \mathrm{C}$.

Stationary-phase cultures were obtained by incubating strain ACAM 342 as above for $48 \mathrm{~h}$ at $15^{\circ} \mathrm{C}$.

Strain ACAM 342 was incubated in high salinity medium by the addition of $3.5 \mathrm{~g} \mathrm{NaCl}$ to Zobell's broth resulting in a total salt concentration of $7.0 \%(\mathrm{w} / \mathrm{v})$. Incubation was for $48 \mathrm{~h}$ as described for standard conditions prior to harvest.

Biotin-enriched medium was produced by the addition of $2 \mathrm{mg}$ biotin $\mathrm{l}^{-1}$ (Sigma) to standard Zobell's broth which was agitated by an orbital shaker (100 r.p.m.) for $20 \mathrm{~h}$ at $15^{\circ} \mathrm{C}$ before harvest.

Low nutrient acetate medium consisted of $0 \cdot 05 \%(\mathrm{w} / \mathrm{v})$ sodium acetate, $0.05 \%(\mathrm{w} / \mathrm{v})$ ammonium nitrate, $1.0 \%(\mathrm{v} / \mathrm{v})$ phosphate supplement and $0.01 \%(\mathrm{w} / \mathrm{v})$ vitamin supplement (Mancuso et al., 1991). Strain ACAM 342 was incubated under the standard conditions given above for $8 \mathrm{~d}$ prior to harvest.

Low nutrient Zobell's broth was produced by the reduction of peptone and yeast extract levels to $0.05 \%(\mathrm{w} / \mathrm{v})$ and $0.01 \%$ (w/v), respectively, compared with that of standard Zobell's broth. The bacterium was incubated in this medium under stadnard conditions for $15 \cdot 5 \mathrm{~h}$.

Desaturase cofactor medium was produced by the addition of $2 \mathrm{mg} \mathrm{NADPH} \mathrm{l}^{-1}$ and $2 \mathrm{mg} \mathrm{FAD}^{-1}$ to Zobell's broth in which $\mathrm{FePO}_{4}$ was also replaced with $\mathrm{FeSO}_{4}$ at the same concentration. Cultures were incubated for $18 \mathrm{~h}$ under standard conditions until harvest.

Culture harvest. Cultures were transferred to chloroformrinsed $250 \mathrm{ml}$ teflon centrifuge bottles containing $150 \mathrm{ml}$ of $0.45 \mu \mathrm{m}$ filtered natural seawater. Following centrifugation at $4600 \mathrm{~g}$ for $25 \mathrm{~min}$, the supernatant was removed and the cell pellet was resuspended in a further $200 \mathrm{ml}$ of $0.45 \mu \mathrm{m}$ filtered natural seawater. Samples were re-centrifuged for $35 \mathrm{~min}$ at $4600 \mathrm{~g}$ and the supernatant was decanted. The remaining cell pellet was resuspended in approximately $3 \mathrm{ml}$ of $0.45 \mu \mathrm{m}$ filtered seawater and transferred to chloroform-rinsed McCartney bottles prior to storage at $-70{ }^{\circ} \mathrm{C}$ until lipid analysis. For quantitative analysis, cell suspensions were transferred to a chloroform-rinsed $30 \mathrm{ml}$ test tube with a known mass of filtered seawater before freeze drying for $48 \mathrm{~h}$. The amount of water lost was then determined, and assuming a seawater salt concentration of $3.5 \%$ and density of $1.04 \mathrm{~g} \mathrm{l}^{-1}$, the mass of salt remaining in the sample was calculated and subtracted from the difference between initial and final test tube weights, to yield the dry mass of cells.

Lipid extraction. Lipids were extracted from cells using a modified one-phase $\mathrm{CHCl}_{3}-\mathrm{MeOH}$ Bligh \& Dyer extraction (Bligh \& Dyer, 1959; White et al., 1979). A portion of the total lipid extract recovered from the lower $\mathrm{CHCl}_{3}$ phase was then saponified by reaction at $80^{\circ} \mathrm{C}$ for $3 \mathrm{~h}$ using $3 \mathrm{ml} 5 \%(\mathrm{w} / \mathrm{v})$ $\mathrm{KOH}$ in $80 \%(\mathrm{v} / \mathrm{v}) \mathrm{MeOH}$. After the addition of water $(1 \mathrm{ml})$ the mixture was extracted with $\mathrm{C}_{6} \mathrm{H}_{14} / \mathrm{CHCl}_{3}(4: 1, \mathrm{v} / \mathrm{v}$; $3 \times 2 \mathrm{ml}$ ) to yield a non-saponifiable neutral lipid fraction contained in the upper organic layer and salts of free fatty acids in the lower aqueous layer. Fatty acids were collected by acidificaton of the remaining aqueous layer with conc. $\mathrm{HCl}$ and extracted with $\mathrm{C}_{6} \mathrm{H}_{14} / \mathrm{CHCl}_{3}(4: 1, \mathrm{v} / \mathrm{v} ; 3 \times 2 \mathrm{ml})$. The solvent was removed under a stream of nitrogen and fatty acids were methylated by reaction for $1 \mathrm{~h}$ at $80^{\circ} \mathrm{C}$ with $\mathrm{MeOH} / \mathrm{HCl} /$ $\mathrm{CHCl}_{3}(10: 1: 1$, by vol., $3 \mathrm{ml})$. After the addition of water $(1 \mathrm{ml})$, the resultant fatty acid methyl esters (FAME) were extracted with $\mathrm{C}_{6} \mathrm{H}_{14} / \mathrm{CHCl}_{3}(4: 1, \mathrm{v} / \mathrm{v} ; 3 \times 2 \mathrm{ml})$. Samples were then diluted for gas chromatographic analysis with $\mathrm{CHCl}_{3}$ 


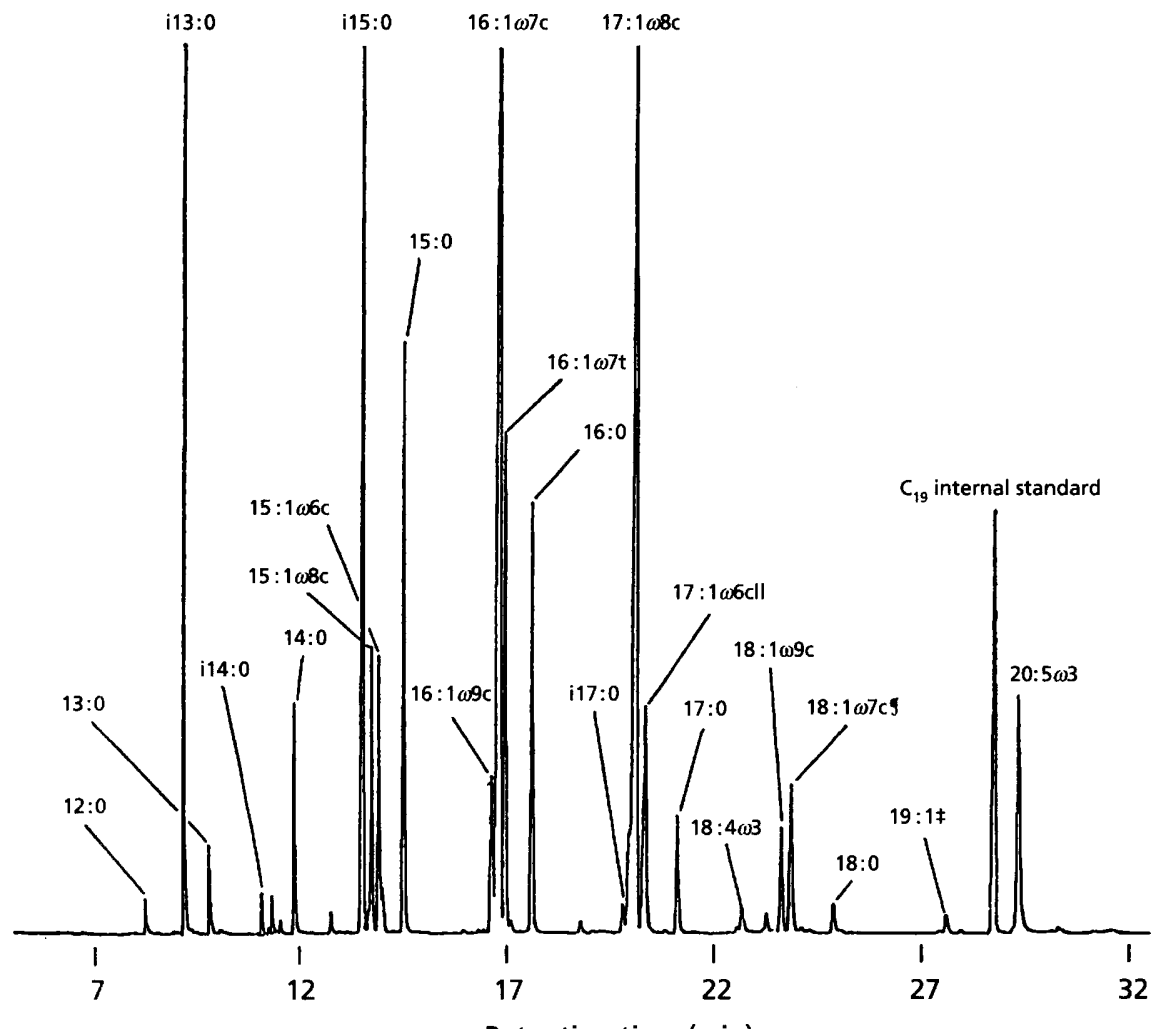

Retention time $(\mathrm{min})$
Fig. 1. Capillary gas chromatogram of fatty acids (as methyl esters) from Shewanella putrefaciens ACAM 342 grown in desaturase-cofactor-supplemented medium. Refer to Table 1 for definition of footnote symbols. containing nonadecanoic acid methyl ester (19:0 Me ester) internal standard of known concentration.

Gas chromatographic analysis. Gas chromatographic (GC) analyses of the FAME were performed with a Hewlett Packard 5890 gas chromatograph equipped with a $50 \mathrm{~m} \times 0.32 \mathrm{~mm}$ internal diameter cross-linked methyl silicone $(0 \cdot 17 \mu \mathrm{m}$ film thickness) fused-silica capillary column and flame ionization detector. Samples were injected at $50^{\circ} \mathrm{C}$ in the splitless mode with a venting time of $2 \mathrm{~min}$. After $1 \mathrm{~min}$ the oven was temperature-programmed from 50 to $150{ }^{\circ} \mathrm{C}$ at a rate of $30^{\circ} \mathrm{C} \mathrm{min}^{-1}$, then at $2{ }^{\circ} \mathrm{C} \mathrm{min}^{-1}$ to $250^{\circ} \mathrm{C}$, and $5^{\circ} \mathrm{C} \mathrm{min}{ }^{-1}$ to a final temperature of $300^{\circ} \mathrm{C}$ which was maintained for $15 \mathrm{~min}$. Hydrogen was used as the carrier gas, and the injector and detector were maintained at 290 and $310^{\circ} \mathrm{C}$, respectively. Peak areas were quantified using chromatography software (DAPA Scientific Software, Kalamunda, Western Australia) on an IBM compatible personal computer. Replicate samples analysed by these procedures have previously been shown to have a SD of less than $5 \%$ for individual components (Edlund et al., 1985).

GC-mass spectrometric (GC-MS) analyses of samples were performed on a Hewlett Packard 5890 GC and 5970 Mass Selective Detector (MSD) fitted with a direct capillary inlet. The column, injector and chromatography conditions were similar to those described above, with helium used as the carrier gas. Mass spectra were acquired and processed using a Hewlett Packard 59970C Workstation operated in scan acquisition mode. Typical MSD operating conditions were: electron multiplier, 2000-2200 V; transfer line, $300{ }^{\circ} \mathrm{C}$; autotune file DFTPP normalized; electron impact energy, $70 \mathrm{eV}$; scan threshold, 1500 ; 0.8 scans s $^{-1}$; mass range, 40-600 atomic mass units; solvent delay, $7 \mathrm{~min}$. Compounds were identified by relative retention time data and from the comparison of mass spectra with those previously reported. Monounsaturated fatty acid double-bond position and geometry were determined by GCMS analysis of the dimethyl disulphide (DMDS) adducts (Dunkelblum et al., 1985; Nichols et al., 1986).

Statistical analysis. A modified Student's $t$-test was used for comparison of the single manipulation observations with the mean of standard condition values, as described in Sokal \& Rohlf (1981) and Rohlf \& Sokal (1981).

\section{RESULTS}

\section{Standard growth conditions}

To compare the effect of various growth conditions on PUFA production by $S h$. putrefaciens strain ACAM 342, cultures were grown in triplicate under standard conditions in Zobell's broth at $15^{\circ} \mathrm{C}$ before cell harvest in exponential phase. The fatty acid composition of the bacterium grown under these standard conditions is given in Table 1 and a sample chromatogram in Fig. 1. The bacterium contained predominantly monounsaturated fatty acids $(58.3 \pm 1.5 \%$ ), with the major components

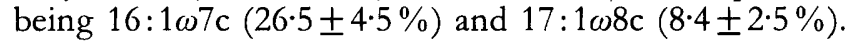
Similar proportions of branched- and straight-chain saturated fatty acids were found $(18.6 \pm 0.8 \%$ and $18.9 \pm$ $2.6 \%$, respectively), with the major components being i15:0 $(10 \cdot 7 \pm 0 \cdot 8 \%)$ and $16: 0(9 \cdot 1 \pm 2 \cdot 3 \%)$. Four polyunsaturated fatty acids were identified and accounted for $3.9 \pm 0.2 \%$ of total fatty acids. The most abundant of these was $20: 5 \omega 3$, present at levels of $3 \cdot 2 \pm 0.3 \%$ $\left[1 \cdot 2 \pm 0 \cdot 2 \mathrm{mg}(\mathrm{g} \text { bacterial dry } \mathrm{wt})^{-1}\right]$ (Table 1$)$. 
Table 1. Fatty acid composition of Shewanella putrefaciens strain ACAM 342 under various culture conditions

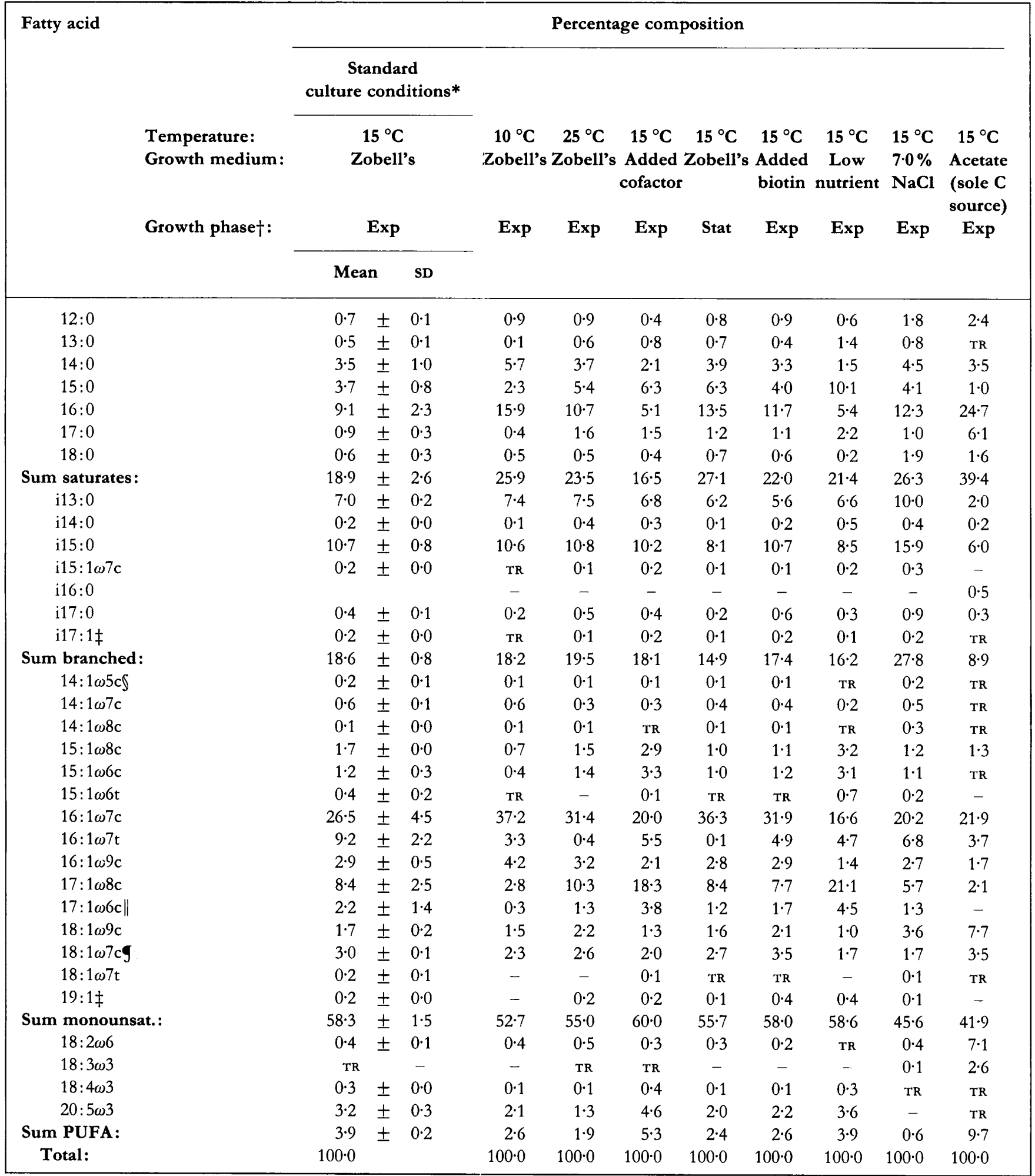

* Data from three replicates.

† Exp, exponential phase; Stat, stationary phase.

$\ddagger$ Double bond position not determined.

$\S$ Plus trace quantities of $14: 1 \omega 5 \mathrm{t}$.

|| Plus trace quantities of $17: 1 \omega 8 \mathrm{t}$.

g Plus trace quantities of $18: 1 \omega 9 \mathrm{t}$. 


\section{Growth phase}

Relative levels of eicosapentaenoic acid (EPA) production were compared in exponential- and stationary-phase cultures. There was a significant decrease $(P<0.05)$ in total PUFA levels from $3 \cdot 9 \pm 0.3 \%$ (exponential) to $2 \cdot 4 \%$ in stationary phase, while the percentage of EPA fell from $3.2 \pm 0.3 \%$ to $2.0 \%(0 \cdot 1>P>0.05)$. There was no significant change $(P>0.05)$ in the level of total monounsaturated or saturated fatty acids with growth phase (Table 1).

\section{Alteration of growth temperature}

The effect of growth of 10,15 and $25^{\circ} \mathrm{C}$ on levels of EPA is shown in Table 1. The percentage of EPA was greatest at $15{ }^{\circ} \mathrm{C}$, accounting for $3 \cdot 2 \pm 0.3 \%$ of total fatty acids. Growth of the organism at $10^{\circ} \mathrm{C}$ did not significantly $(P$ $>0.05)$ alter the percentage of EPA. However, growth at $25^{\circ} \mathrm{C}$ led to a decrease in the level of EPA to $1.3 \%(P<$ $0 \cdot 05$ ).

\section{Addition of $\mathrm{NaCl}$}

An increase in the salinity of the medium from 3.5 to $7.0 \%$ greatly reduced cell yield and the overall level of fatty acid unsaturation. This effect was observed both in the level of total monounsaturated fatty acids, which fell from $58.3 \pm 1.5 \%(3.0 \% \mathrm{NaCl})$ to $45.6 \%(7.0 \% \mathrm{NaCl})(P<$ 0.02 ) and PUFA, which decreased from $3.9 \pm 0.2 \%$ to only $0.6 \%$ of total fatty acids as salinity was increased $(P$ $<0.01)$. The majority of this decrease was due to a lower level of EPA, which was not detected in cultures grown at $7 \cdot 0 \%$ salinity.

\section{Addition of biotin}

There were no significant $(P>0 \cdot 05)$ alterations in the fatty acid percentage composition with the addition of a $2 \mathrm{mg}$ biotin $\mathrm{l}^{-1}$ supplement to the standard medium, although levels of EPA were seen to drop from $3 \cdot 2 \pm 0.3 \%$ (screening media) to $2 \cdot 2 \%$ (biotin-supplemented media). The production of EPA also fell from $1.2 \pm 0.2 \mathrm{mg}$ ( $\mathrm{g}$ bacterial dry wt $)^{-1}$ in screening media to $0.6 \mathrm{mg}$ ( $\mathrm{g}$ bacterial dry $\mathrm{wt})^{-1}$ of cells in the biotin-supplemented medium.

\section{Low nutrient Zobell's broth}

The fatty acid composition of strain ACAM 342 cultured in low nutrient Zobell's medium is shown in Table 1. The total levels of major fatty acid groups (saturated, branched, monounsaturated and PUFA) remained relatively constant $(P>0.05)$, as did the percentage and overall yield of EPA [screening media: $3.2 \pm 0.3 \%$, $1 \cdot 2 \pm 0.2 \mathrm{mg}$ (g bacterial dry wt $)^{-1}$; low nutrient media: $3.6 \%, 1.1 \mathrm{mg}$ (g bacterial dry $\mathrm{wt})^{-1}$ ].

\section{Growth on acetate}

The proportion of straight-chain saturated fatty acids increased substantially $(P<0.05)$ from $18.9 \pm 2.6 \%$ under standard culture conditions to $39 \cdot 4 \%$ in the culture grown with acetate as the sole carbon source. This was accompanied by a significant decrease $(P<0.01)$ in the level of branched-chain fatty acids from $18.6 \pm 0.8 \%$ (standard conditions) to $8.9 \%$ in the acetate-grown culture. Total PUFA levels also increased $(P<0.01)$ from $3.9 \pm 0.2 \%$ to $9 \cdot 7 \%$, which was due mainly to levels of $18: 2 \omega 6$ which rose from $0 \cdot 4 \pm 0 \cdot 1 \%$ (standard conditions) to $7 \cdot 1 \%$ in cells grown on acetate. However, levels of EPA decreased to only trace amounts.

\section{Addition of desaturase cofactors}

The fatty acid composition of strain ACAM 342 grown in standard screening media to which $2 \mathrm{mg} \mathrm{NADPH} 1^{-1}$, $2 \mathrm{mg} \mathrm{FAD} \mathrm{l}^{-1}$ and $10 \mathrm{mg} \mathrm{FeSO}_{4} \mathrm{l}^{-1}$ had been added is shown in Table 1. Addition of desaturase cofactors significantly increased $(P<0.05)$ the percentage of total PUFA from $3 \cdot 9 \pm 0 \cdot 2 \%$ (standard conditions) to $5 \cdot 3 \%$. A major component of this increase was the level of EPA which rose from $3 \cdot 2 \pm 0 \cdot 3 \%$ to $4 \cdot 6 \%$ of total fatty acids, the highest proportion achieved under any of the growth conditions.

\section{DISCUSSION}

Cellular fatty acid composition may vary with growth phase (e.g. Kaneda, 1966, 1977; Oliver \& Colwell, 1973). A comparison of stationary- and exponential-phase cultures of strain ACAM 342 showed an overall decrease in EPA and total PUFA $(P<0 \cdot 05)$. This indicates a general decrease in the activity of PUFA synthesis with culture age. A similar effect was observed in two marine strains, where levels of 18:2 decreased sharply with culture age (Oliver \& Colwell, 1973). It appears that strain ACAM 342 possessed either a different regulatory desaturase mechanism to that of B. megaterium (Fujii \& Fulco, 1977), or if there was an increase in desaturase activity in stationary phase cells, this was not manifested by an increase in the level of EPA.

A study of five psychrotrophic Psendomonas sp. by Bhakoo \& Herbert (1980) demonstrated no significant change in fatty acid composition when the incubation temperature was reduced from 20 to $0{ }^{\circ} \mathrm{C}$. It was suggested that the high levels of unsaturated fatty acids in these organisms grown at $20^{\circ} \mathrm{C}(59-71 \%)$ allowed sufficient membrane fluidity to be maintained for proper cellular function at the lower temperature. A similar trend was found for a psychrophilic Vibrio sp., which contained over $68 \% 16: 1$ when grown at $15{ }^{\circ} \mathrm{C}$, but did not significantly alter its fatty acid composition when transferred to $0^{\circ} \mathrm{C}$ (Bhakoo $\&$ Herbert, 1979). Three further strains, which contained only $0-22 \% 16: 1$ at $15{ }^{\circ} \mathrm{C}$, increased the degree of fatty acid unsaturation significantly when transferred to $0{ }^{\circ} \mathrm{C}$. Further evidence of this effect was observed by Tsien $e t a l$. (1980) for Streptococcus mutans which constructed its membrane at a given temperature with sufficient fluidity to allow survival and growth at suboptimal temperatures.

These previous studies provide a basis for the interpretation of the temperature effects observed on the fatty acid composition of ACAM 342. The high level of monounsaturated $(58.3 \pm 1.5 \%)$, branched $(18.6 \pm 0.8 \%)$ and 
PUFA components $(3.9 \pm 0.2 \%)$ at $15{ }^{\circ} \mathrm{C}$ provided suf. ficient membrane fluidity to withstand the drop in temperature to $10^{\circ} \mathrm{C}$ without inducing significant $(P<$ $0.05)$ changes in overall fatty acid composition. Growth of ACAM 342 at $25^{\circ} \mathrm{C}$ demonstrated a more classical homeoviscous response (Sinensky, 1974). As growth temperature was increased, a lesser degree of fluidity was required, leading to the observed decrease in the ratio of unsaturated to saturated fatty acids. This was particularly evident in levels of PUFA.

Adaptation to water stress is often accompanied by modification of membrane permeability in response to osmotic forces (Brown, 1979). McMeekin et al. (1971) showed that ACAM 342 grew in media containing $5.0 \%$ $\mathrm{NaCl}$ but not $10 \cdot 0 \%$. The bacterium was grown therefore in $7.0 \% \mathrm{NaCl}$ medium to compare the fatty acid composition with that determined under standard growth conditions, which contained seawater as the sole $\mathrm{NaCl}$ source. Growth at $7 \cdot 0 \%$ salinity markedly reduced $(P<$ $0.02)$ the overall level of fatty acid unsaturation, particularly contents of EPA and total PUFA. This change in membrane composition, which would be expected to increase membrane rigidity, suggests that ACAM 342 was nearing its limit of salt tolerance, resulting in suboptimal growth.

The Shewanella (Alteromonas)-like EPA producers reported by both Wirsen et al. (1987) and Yazawa et al. (1988a, b) contained little or no branched fatty acids, and appeared to regulate their membrane fluidity through alteration of PUFA levels. Sh. putrefaciens, ACAM 342 and S29 (Matsui et al., 1991) do however, contain a significant proportion of branched-chain components. The production of branched-chain fatty acids has been recognized as an alternative strategy for maintaining membrane fluidity (Kaneda, 1991). The much lower levels of PUFA production from strains ACAM 342 and S29 may be due to a large proportion of the required membrane fluidity being provided by these branched components. It was proposed therefore that if the proportion of branched-chain components could be reduced, the bacterium may increase PUFA levels to compensate for the loss of branched-chain fluidizing components.

One strategy considered to achieve this reduction in branched-chain fatty acids, and a possible rise in PUFA levels, was the addition of a biotin supplement to the medium. Growth with biotin supplementation however, produced no significant $(P>0.05)$ alteration in fatty acid composition, implying that ACAM 342 does not require biotin, or that sufficient biotin was already present in the screening medium. While the percentage of EPA in cells grown in the biotin-supplemented medium fell slightly, there was also a decrease in the quantitative yield of EPA from $1.2 \pm 0.2$ to $0.56 \mathrm{mg}$ ( $\mathrm{g}$ bacterial dry wt $)^{-1}(0.2>P$ $>0 \cdot 1$ ). This may suggest an overall decrease in fatty acid synthesis elicited by the high levels of biotin, an opposite effect to that observed for B. subtilis and B. cereus (Kaneda, 1966; Hubbard \& Hall, 1968).

Synthesis of branched-chain fatty acids relies on the provision of specific branched-chain precursor molecules that replace acetate as the fatty acid chain primer. The majority of these are derived from the amino acids valine, leucine and isoleucine, supplied in the growth medium (Kaneda, 1977, 1991). The presence of yeast extract and peptone as the major nutrient sources in Zobell's medium would have provided a source of these amino acids. It was postulated that removal of all exogenous sources of amino acids from the growth medium would restrict branchedchain fatty acid production, and therefore possibly induce an increase in PUFA to compensate for the loss of these fluidizing components.

A substantial decrease $(P<0.01)$ in the percentage of branched-chain fatty acids was achieved by growth of ACAM 342 utilizing acetate as the sole carbon source (Table 1). As expected, the percentage of straight-chain saturated fatty acids also rose sharply $(P<0.05)$ with the utilization of acetate as the predominant chain primer. The bacterium therefore underwent a major alteration of fatty acid composition in which a large proportion of the branched lower melting-point membrane components were replaced with higher melting-point straight-chain saturated species, presumably reducing membrane fluidity (Melchior, 1982). As was hypothesized, to counteract this effect a sharp rise in PUFA components $(P<0.02)$ was observed, largely due to $18: 2 \omega 6$ and, to a lesser extent, $18: 3 \omega 3$. More highly unsaturated components, $18: 4 \omega 3$ and EPA, decreased in comparison with cultures grown under standard conditions. Presumably, ACAM 342 utilized an aerobic pathway for PUFA synthesis, which may be similar to that of eukaryotes (Fulco, 1983; Nichols et al., 1993). Limitation of any essential cofactors may inhibit production of the more highly unsaturated fatty acids.

Growth of ACAM 342 in low nutrient Zobell's broth had no major effect $(P>0.05)$ on fatty acid composition or EPA production. Similar nutrient levels to full strength Zobell's broth were used by Akimoto et al. (1990) to maximize EPA production from strain SCRC-2738. Our results indicate that a further 10 -fold reduction in nutrient levels has no major effect on EPA production by strain ACAM 342.

While no de novo PUFA synthetic mechanism from bacteria has been elucidated, by analogy with eukaryotic mechanisms, it is assumed to involve an aerobic process (Fulco, 1983). The electron transport chain associated with desaturase enzyme action requires several cofactors: oxygen, $\mathrm{Fe}(\mathrm{II}), \mathrm{NADPH}$ and FAD in the case of Mycobacterium pblei (Fulco \& Bloch, 1964). However, the majority of studies concerning bacterial desaturase systems have employed cell-free extracts. Therefore, the relationship between exogenous cofactor supply and whole cells has remained uninvestigated, apart from a somewhat analogous study utilizing suspensions of plant chloroplasts (Stumpf \& James, 1963). In the present study, exogenous desaturase cofactors were added to a viable culture and the effect on cellular PUFA levels monitored. Addition of desaturase cofactors to the standard medium increased the total percentage of PUFA $(P<0 \cdot 05)$, particularly $18: 4 \omega 3$ and EPA. While the 
percentage of EPA increased, there was no significant change $(P>0.05)$ in the quantitative yield $[\mathrm{mg}(\mathrm{g}$ bacterial dry wt $)^{-1}$ ], suggesting a slight reduction in the fatty acid content of cultures grown under cofactor supplementation, as occurred in biotin-supplemented cultures. This result suggests that the addition of excess cofactors may have stimulated additional synthesis of PUFA.

The trans-monounsaturated fatty acid $16: 1 \omega 7 \mathrm{t}$ occurred under all culture conditions, including growth on acetate as the sole carbon source, together with four other transisomers $14: 1 \omega 5 \mathrm{t}, 15: 1 \omega 6 \mathrm{t}, 17: 1 \omega 8 \mathrm{t}$ and $18: 1 \omega 7 \mathrm{t}$ under various culture conditions. Although de novo synthesis of trans-fatty acids has been reported in several cases, no firm biosynthetic mechanism has been established for their synthesis. Trans-fatty acids have not been reported previously from $S b$. putrefaciens strains (Wilkinson \& Caudwell, 1980; Moule \& Wilkinson, 1987). This in itself, however, may not be surprising. Wilkinson \& Caudwell (1980) did not determine the double bond position of monounsaturated fatty acids, and would therefore not have been able to identify any trans-fatty acids present. Moule \& Wilkinson (1987) did identify double bond position by mass spectral analysis of picolinyl ester derivatives (Wait \& Hudson, 1985). It is possible that the GC conditions employed were not adequate to achieve separation of closely eluting cis- and trans-isomers. The production of trans-fatty acids has been suggested to be an indicator of starvation or environmental stress (Guckert et al., 1986). This would not appear to be the case for ACAM 342. The bacterium produced significant levels of trans-fatty acids under standard growth conditions of $15^{\circ} \mathrm{C}$ in Zobell's broth, conditions that would not induce a starvation or stress response. Also, there was no correlation between the ratio of cis/trans fatty acids and the potential levels of stress caused by the various manipulations. Okuyama et al. (1991) demonstrated a relationship between incubation temperature of Vibrio sp. strain ABE-1 and the level of $16: 1 \omega 7 \mathrm{t}$ produced by the bacterium, and proposed the production of trans-fatty acids as an adaptive response to changes in growth temperature by this strain. ACAM 342, however, showed no clear relationship between the level of trans-fatty acids and growth temperature between 10 and $25^{\circ} \mathrm{C}$. All transdouble bonds produced by ACAM 342 are in the $\Delta^{9}$ or $\Delta^{11}$ positions. These are common $c i s-\Delta$ positions produced by the anaerobic pathway, and suggest that a direct isomerization mechanism of cis to trans double bonds may be involved, as proposed by Guckert et al. (1987) and Okuyama et al. (1991).

\section{ACKNOWLEDGEMENTS}

This work was supported in part by the Antarctic Science Advisory Committee, the CSIRO-University of Tasmania grants scheme and the Australian Research Council. We thank Dr P. D. Franzmann and C. A. Mancuso for advice during experimental work; G. Dunstan and P. Virtue for helpful comments during manuscript preparation; K. Swadling for statistical advice; and M. Salter for provision of ACAM 342 growth curve.

\section{REFERENCES}

Akimoto, M., Ishii, T., Yamagaki, K., Ohtaguchi, K., Koide, K. \& Yazawa, K. (1990). Production of eicosapentaenoic acid by a bacterium isolated from mackerel intestines. J Am Oil Chem Soc 67, 911-915.

Bell, J. G., McVicar, A. H., Park, M. T. \& Sargent, J. R. (1991). High dietary linoleic acid affects the fatty acid composition of individual phospholipids from tissues of atlantic salmon (Salmo salar): association with stress susceptibility and cardiac lesion. $J$ Nutr 121, $1163-1173$.

Bhakoo, M. \& Herbert, R. A. (1979). The effects of temperature on the fatty acid and phospholipid composition of four obligately psychrophilic Vibrio sp. Arch Microbiol 121, 121-127.

Bhakoo, M. \& Herbert, R. A. (1980). Fatty acid and phospholipid composition of five psychrotrophic Pseudomonas sp. grown at different temperatures. Arch Microbiol 126, 51-55.

Bligh, E. G. \& Dyer, W. J. (1959). A rapid method for total lipid extraction and purification. Can J Biochem Pbysiol 37, 911-917.

Brown, A. D. (1979). Physiological problems of water stress. In Strategies of Microbial Life in Extreme Environments, pp. 65-81. Edited by M. Shilo, Berlin: Dahlem Konferenzen.

Cronan, J. E. \& Gelmann, E. P. (1975). Physical properties of membrane lipids: Biological relevance and regulation. Bacteriol Rev 39, 232-256.

DeLong, E. F. \& Yayanos, A. A. (1986). Biochemical function and ecological significance of novel bacterial lipids in deep-sea prokaryotes. Appl Environ Microbiol 51, 730-737.

Dunkelblum, E., Tan, S. H. \& Silk, P. J. (1985). Double-bond location in monounsaturated fatty acids by dimethyl disulphide derivatisation and mass spectroscopy. J Chem Technol 11, 265-277.

Fujii, D. K. \& Fulco, A. J. (1977). Biosynthesis of unsaturated fatty acids by bacilli: hyperinduction and modulation of desaturase synthesis. J Biol Chem 252, 3660-3670.

Fukunaga, N. \& Russell, N. J. (1990). Membrane lipid composition and glucose uptake in two psychrotolerant bacteria from Antarctica. J Gen Microbiol 136, 1669-1673.

Fulco, A. J. (1983). Fatty acids of bacteria. Prog Lipid Res 22, 133-160.

Fulco, A. J. \& Bloch, K. (1964). Cofactor requirements for the formation of $\Delta^{9}$-unsaturated fatty acids in Mycobacterium phlei.J Biol Chem 239, 993-997.

Guckert, J. B., Ringelberg, D. B. \& White, D. C. (1986). Biosynthesis of trans-fatty acids from acetate in the bacterium Pseudomonas atlantica. Can J Microbiol 33, 748-754.

Guckert, J. B., Hood, M. A. \& White, D. C. (1987). Phospholipid ester-linked fatty acid profile changes during nutrient deprivation of Vibrio cholerae: increases in the trans/cis ratio and proportions of cyclopropyl fatty acids. Appl Environ Microbiol 52, 794-801.

Hubbard, J. S. \& Hall, A. N. (1968). Effects of biotin on glutamate production and fatty acid composition of Bacillus cereus 14B22. Can J Microbiol 14, 1039-1048.

Intriago, P. \& Floodgate, G. D. (1991). Fatty acid composition of the estuarine Flexibacter sp. strain Inp: effect of salinity, temperature and carbon source for growth. J Gen Microbiol 137, 1503-1508.

Jacq, E., Prieur, D., Nichols, P., White, D. C., Porter, T. \& Geesey, G. G. (1989). Microscopic examination of filamentous bacteria colonising substrata around subtidal hydrothermal vents. Arch Microbiol 152, 64-71.

Johns, R. B. \& Perry, G. J. (1977). Lipids of the bacterium Flexibacter polymorphus. Arch Microbiol 114, 267-271. 
Kaneda, T. (1966). Biosynthesis of branched-chain fatty acids IV. Factors affecting relative abundances of fatty acids produced by Bacillus subtilis. Can J Microbiol 12, 501-514.

Kaneda, T. (1977). Fatty acids of the Genus Bacillus: an example of branched-chain preference. Bacteriol Rev 41, 391-418.

Kaneda, T. (1991). Iso- and anteiso-fatty acids in bacteria: biosynthesis, function and taxonomic significance. Microbiol Rev 55, 288-302.

Kelly, F. J. (1991). The metabolic role of n-3 PUFA: relationship to human disease. Comp Biochem Pbysiol 98A, 581-585.

Langdon, C. J. \& Waldock, M. J. (1981). The effect of algal and artificial diets on the growth and fatty acid composition of Crassostera gigas spat. J Mar Biol Assoc UK 61, 431-448.

McMeekin, T. A., Patterson, J. T. \& Murray, J. G. (1971). An initial approach to the taxonomy of some gram-negative yellow pigmented rods. J Appl Bacteriol 34, 699-716.

Mancuso, C. A., Sanderson, K., Franzmann, P. D., McMeekin, T. A. \& Burton, H. R. (1991). Australian Collection of Antarctic Microorganisms: a catalogue of strains. ANARE Research Notes 83, Antarctic Division, Hobart.

Matsui, Y., Suzuki, S., Suzuki, T. \& Takama, K. (1991). Phospholipid and fatty acid compositions of Alteromonas putrefaciens and $A$. baloplanktis. Lett Appl Microbiol 12, 51-53.

Melchior, D. L. (1982). Lipid phase transitions and regulation of membrane fluidity in prokaryotes. Curr Top Membr Transp 17, 263-307.

Moule, A. L. \& Wilkinson, S. G. (1987). Polar lipids, fatty acid and quinones of Alteromonas putrefaciens (Shewanella putrefaciens). Syst Appl Microbiol 9, 192-198.

Nichols, D. S., Nichols, P. D. \& McMeekin, T. A. (1992). Anaerobic production of polyunsaturated fatty acids by Shewanella putrefaciens strain ACAM 342. FEMS Microbiol Lett 98, 117-122.

Nichols, D. S., Nichols, P. D. \& McMeekin, T. A. (1993). Polyunsaturated fatty acids from Antarctic bacteria. Antarct Sci 5 , 149-160.

Nichols, P. D., Guckert, J. B. \& White, D. C. (1986). Determination of monounsaturated fatty acid double-bond position and geometry for microbial monocultures and complex consortia by capillary GCMS of their dimethyl disulphide adducts. $J$ Microbiol Methods 5, 49-55.

Okuyama, H., Okajima, N., Sasaki, S., Higasi, S. \& Murata, N. (1991). The cis/trans isomerization of the double bond of a fatty acid as a strategy for adaptation to changes in ambient temperature in the psychrophilic bacterium, Vibrio sp. strain ABE-1. Biocbim Biopbys Acta 1084, 13-20.

Oliver, J. D. \& Colwell, R. R. (1973). Extractable lipids of Gramnegative marine bacteria : fatty acid composition. Int I Syst Bacteriol 23, 442-458.

Ringø, E., Jøstensen, J. P. \& Olsen, R. E. (1992). Production of eicosapentaenoic acid by freshwater Vibrio. Lipids 27, 564-566.

Rohlf, F. J. \& Sokal, R. R. (1981). Statistical Tables. New York: W. H. Freeman.

Russell, N. J. (1984). Mechanisms of thermal adaptation in bacteria : blueprints for survival. Trends Biocbem Sci 9, 108-112.
Sinensky, M. (1974). Homeoviscous adaption - a homeostatic process that regulates the viscosity of membrane lipids in E. coli. Proc Natl Acad Sci US A 71, 522-525.

Sokal, R. R. \& Rohlf, F. J. (1981). Biometry. The Principles and Practice of Statistics in Biological Research. New York: W. H. Freeman.

Stansby, M. E. (1990). Nutritional properties of fish oil for human consumption-modern aspects. In Fish Oils in Nutrition, pp. 289-308. Edited by M. E. Stansby. New York: Van Nostrand Reinhold.

Stumpf, P. K. \& James, A. T. (1963). The biosynthesis of long-chain fatty acids by lettuce chloroplast preparations. Biocbim Biophys Acta 70, 20-32.

Suzuki, N., Inoue, A., Shikano, M., Yazawa, K. \& Kondo, K. (1991). Effect of arginine on the production of eicosapentaenoic acid (EPA) in EPA-elaborating bacterium SCRC-2738. Nippon Suisan Gakkaishi 57, 1407.

Suzuki, N., Yazawa, K., Watanabe, K., Akahori, Y., Ishikawa, C., Kondo, K. \& Takada, K. (1992). Culture conditions of marine bacterium SCRC-2738 for the production of eicosapentaenoic acid (EPA). Nippon Suisan Gakkaishi 58, 323-328.

Temara, A., DeRidder, C. \& Kaisin, M. (1991). Presence of an essential polyunsaturated fatty acid in intradigestive bacterial symbionts of a deposit-feeder echinoid (Echinodermata). Comp Biochem Physiol 100B, 503-505.

Tsien, H., Panos, C., Shockman, G. D. \& Higgins, M. L. (1980). Evidence that Streptococcus mutans constructs its membrane with excess fluidity for survival at suboptimal temperatures. $J$ Gen Microbiol 121, 105-111.

Wait, R. \& Hudson, M. J. (1985). The use of picolinyl esters for the characterisation of microbial lipids: application to the unsaturated and cyclopropane fatty acids of Campylobacter sp. Lett Appl Microbiol 1, 95-99.

Weber, L. (1991). n-3 Fatty acids and human disease. Scand J Clin Lab Invest Suppl 50 (Supp. 202), L2-19.

White, D. C., Davis, W. M., Nickels, J. S., King, J. D. \& Bobbie, R. J. (1979). Determination of the sedimentary microbial biomass by extractible lipid phosphate. Oecologica 40, 51-62.

Wilkinson, S. G. \& Caudwell, P. F. (1980). Lipid composition and chemotaxonomy of Pseudomonas putrefaciens (Alteromonas putrefaciens). J Gen Microbiol 118, 329-341.

Wirsen, C. O., Jannasch, H. W., Wakeham, S. G. \& Canuel, E. A. (1987). Membrane lipids of a psychrophilic and barophilic deep-sea bacterium. Curr Microbiol 14, 319-322.

Yazawa, K., Araki, K., Okazaki, N., Watanabe, K., Ishikawa, C., Inoue, A., Numao, N. \& Kondo, K. (1988a). Production of eicosapentaenoic acid by marine bacteria. J Biochem 103, 5-7.

Yazawa, K., Araki, K., Okazaki, N., Watanabe, K., Ishikawa, C., Inoue, A., Numao, N. \& Kondo, K. (1988b). Eicosapentaenoic acid productivity of the bacteria isolated from fish intestines. Nippon Suisan Gakkaishi 54, 1835-1838.

Zobell, C. E. (1946). Marine Microbiology. Waltham: Chronica Botanica.

Received 17 May 1993; revised 24 September 1993; accepted 1 October 1993. 